\title{
Social and Technological Development Projects in Argentina and the need for a system for ex post evaluation
}

\author{
Giordano Lerena, Roberto, Specialist engineer in technology and innovation management ${ }^{1,2}$, \\ Armando Fernández Guillermet, $\mathrm{PhD}$ in Physical Metallurgy ${ }^{3,4}$ \\ ${ }^{1}$ Faculty of Engineering, FASTA University, Argentina, rogiord@ufasta.edu.ar \\ ${ }^{2}$ Faculty of Engineering, National University of Mar del Plata, Argentina \\ ${ }^{3}$ Balseiro Institute and Faculty of Exact and Natural Sciences, National University of Cuyo, Argentina \\ ${ }^{4}$ CONICET, Argentina, a.f.guillermet@gmail.com
}

\begin{abstract}
In 2013 the Argentinian Republic incorporated to the Scientific and Technological National System a recognition and rating instrument of the technological development activities with social impact. The instrument integrates a System that works in the frame of State policies that allows the accreditation of the Social and Technological Development Projects (PDTS) and its incorporation to the National Bank of such projects.

As the System is consolidated, the challenge that arises now is to generate an ex post System of Evaluation of the PDTS, which makes it possible to validate its effectiveness in terms of impact and compliance with the criteria evaluated ex ante. For this reason, the development of an Ad-hoc Evaluation Technology is proposed.

The article presents the background, characteristics, and implementation details of the System and the PDTS as an instrument, in order to disseminate it in the region and, especially, in the field of engineering. It also exposes the conceptual framework for the development of the necessary technology for the ex post evaluation of this type of projects.
\end{abstract}

Keywords-Technological development; Social and Technological Development Projects; Science and Technology Systems.

\section{INTRODUCTION}

In August 2012 the Ministry of Science, Technology and Productive Innovation of the Argentine Nation - MCTIP published an agreement called "Document I of the Advisory Committee on Evaluation of Scientific and Technological Personnel: Towards a redefinition of the criteria for evaluation of scientific and technological personnel"[1].

This Document I is a historical milestone in terms of the policy of recognition of research and technological development in Argentina, since it expresses the need for a new system of evaluation of science and technology activities "where a balance is achieved between originality criteria and applicability criteria, taking into account that the current system overvalues originality through the measurement of impact variables of scientific and technological production, while there is no consensus on the ways of measuring applicability and impact of social and technological developments".

Digital Object Identifier (DOI):

http://dx.doi.org/10.18687/LACCEI2020.1.1.43

ISBN: 978-958-52071-4-1 ISSN: 2414-6390
In addition, it states "The non-relevance of applying evaluation criteria of personnel dedicated to basic research to personnel dedicated to applied research and social and technological development" and proposes that work should be carried out following "the development of targeted evaluation guidelines to overcome the traditional measurement scheme based on the linear model of knowledge production".

In July 2013, the MCTIP presented a second consensus called: "Document II of the Advisory Committee on Evaluation of Scientific and Technological Personnel: Details about the definition and mechanisms for incorporating Social and Technological Development Projects - PDTS into the National Bank of MCTIP Projects" [2] which foresees the creation of a National PDTS Bank and emphasizes that "The process of incorporating PDTS into the National Bank does not imply the consideration of general characteristics of the $\mathrm{I}+\mathrm{D}$ projects. Instead, it meets the criteria of incorporation that seek to qualify projects based on their contribution to the resolution of problems, needs or demands identifiable in society and / or expressed by social agents in the sphere of politics, market, territory, culture or social structure", expressly mentioning that "The incorporation of a project to the National Bank as PDTS must interactively consider the set of criteria mentioned above, although these criteria may assume different values for each project. Thus, for example, a PDTS with a low level of novelty or local originality in knowledge can be admitted for its high relevance value or for responding to a strategic demand". In addition, it argues that "It is necessary to redefine the concept of novelty or originality of knowledge to a meaning limited to local conditions: it is, then, to understand the question of originality in the sense of 'local novelty"”.

In November 2013, the MCTIP formed four PDTS accreditation commissions, under the Secretariat of ScientificTechnological Articulation - SACT; one for each large area of knowledge: a) Agricultural, Engineering and Material Sciences, b) Biological and Health Sciences, c) Exact and Natural Sciences, d) Social Sciences and Humanities. Each commission has 10 members. 4 are representatives of the universities ( 2 by the National Interuniversity Council CIN and 2 by the Council of Rectors of Private Universities CRUP), 4 are representatives of Science and Technology 
organizations, one is a representative of the Secretariat of University Policies and another of the SACT of the MCTIP.

The PDTS accreditation commissions are spaces, coordinated by the MCTIP, which have the attribution of managing the incorporation of Projects to the BNPDTS National Bank. This incorporation does not include the evaluation of projects, nor is it linked to the evaluation of the personnel that participate in them, which remains in the orbit of each of the institutions that make up the National Scientific and Technological System (SCyTN). These commissions only accredit projects voluntarily submitted for consideration, to be incorporated into BNPDTS. Thus, the PDTS that intend to join the National Bank are analyzed by the corresponding Accreditation Commission that determines, through a series of common and agreed procedures and criteria, if they meet the necessary requirements to be included in the BNPDTS.

This modality seeks to guarantee the homogeneous application of the PDTS concept to projects registered in the BNPDTS that functions as an instrument for the visibility and dissemination of social and technological developments carried out in the country [3].

The BNPDTS has registered 346 accredited projects until 2019 [4]. More than half of them (188) correspond to the area of Engineering, Agronomy and Materials. The other three areas each have, practically, a third of the rest [5].

Two key aspects of this new vision about the recognition of scientific-technological activity at the national level are: (A) the process of building the necessary consensus for its design and implementation; and, (B) the regulatory infrastructure designed to provide continuity and sustainability.

\section{A. Construction and sustainability of consensus}

The aforementioned documents were the product of extensive meetings and debates, with the participation of the key actors of the SCyTN. Among its subscribers, it is worth mentioning the National Council of Scientific and Technical Research, the National Interuniversity Council, the Council of Rectors of Private Universities, the National Commission for University Evaluation and Accreditation, the National Institute of Industrial Technology, the National Institute of Agricultural Technology, the National Atomic Energy Commission, the National Space Activities Commission, the National Water Institute, the Scientific Research Institute for Defense, the National Administration of Health Laboratories and Institutes, the National Fisheries Research and Development Institute, the Argentine Mining Geological Service, the Argentine Antarctic Institute, the Secretariat of University Policies of the Ministry of Education and the Scientific Research Commission of the Province of Buenos Aires.

This consensus means a kind of guarantee, which is fundamental, for the consistency and institutional political support of social technological development activities and the criteria for their accreditation.

\section{B. Regulatory Infrastructure}

The MCTIP had formalized by means of Resolution 007/2012 the formation of the Advisory Committee on Evaluation of Scientific and Technological Personnel that achieved the agreements signed in Document I and Document II of the mentioned commission. These documents imply the formal incorporation into the SCyTN of a recognition of the activities of Social Technological Development.

Through Resolution 303/2014 of the Ministry, the commission for the accreditation of Social Technological Development Projects is formalized so that it determines which projects meet the requirements to be incorporated into the BNPDTS.

Finally, by means of resolution 118/2017 of the same Ministry, the "Regulation of the Commissions for Accreditation of Social and Technological Development Projects (PDTS)" that establishes the functions of these commissions is formalized, while their main objective is "to evaluate compliance of the projects submitted for accreditation, and see if they meet the criteria and necessary requirements to be included in the National PDTS Bank managed by the Ministry of Science, Technology and Productive Innovation (MINCyT) and also recommend their accreditation".

Since the implementation of the system, the accreditation of the PDTS is formalized through resolutions of the Secretariat of Scientific-Technological Articulation of the Ministry of Science, Technology and Innovation (2020).

All these formal instruments give an account of the regulatory infrastructure that supports the recognition of Social Technological Development activities within the framework of the SCyTN and Law 25.467 of Science, Technology and Innovation that establishes that the evaluation of scientific and technological activity constitutes an permanent obligation of the State, which will aim to assess the quality of work of scientists and technologists, allocate resources for science and technology and estimate the linkage of these activities with social objectives. This normative infrastructure sets a systemic frame of reference that remains consistent despite the fluctuations that the policies oriented to the development of PDTS in the local context may suffer.

\section{SOCIAL AND TECHNOLOGICAL DEVELOPMENT PROJECTS}

Certain activities that make up the scientific and technological production of universities, research centers and science and technology organizations are likely to be defined as PDTS and may be accredited by the MCTIP to be included in the National Bank to the extent that they comply with all the characteristics that define them as such, depending on the context in which these activities are found.

A PDTS Social and Technology Development Project is an activity project that: 
- makes use of scientific and technological knowledge belonging to one or more disciplines

- It is composed of elements of different types (such as theoretical background, methodologies and techniques, specific information, phases, technical and financial resources, expertise, ethical and social legitimacy, evaluative criteria of the same activity) sufficiently explicit and ordered so as to allow the understanding of its aims and objectives, the scope of the proposed cognitive progress, the feasibility of its realization, the evaluation of its management, progress and achievements

- aims to solve problems or needs of a practical nature; that is, problems and needs not justified in scientific curiosity alone, the advancement of disciplinary knowledge or the solution of theoretical unknowns, but problems or needs framed in society, politics, economy or the market

- It is problem solving oriented - whether it involves technology, a regulatory framework, a program of intervention in society, a prospective or evaluation of processes and products - that can be replicable models or only applicable to a single case

- has an objective that must be justified in a national, regional, or local interest

- it is proposed to tackle the resolution of problems and / or needs by incorporating cognitive innovations; that is, it is not limited to the application of procedures, routines, methodologies, findings, affirmations of knowledge, etc., already codified and standardized in the knowledge stock of the disciplines of the project, even if these elements are part of it

- identifies one or more public or private organizations that specifically demand and/or are potential adopters of the developed result

- has one or more promoting institutions that will provide, guarantee, or contribute to its financing; and

- has a previous evaluation carried out in the institution that presents the project to the National Bank by specialists or qualified members, which will include: 1) technical and economic-financial feasibility or its equivalent; 2) adequacy of the committed resources (human, infrastructure and equipment, and financing strategies); and 3) progress reports on project execution when appropriate.

\section{ACCREDITATION OF SOCIAL AND TECHNOLOGICAL DEVELOPMENT PROJECTS}

Regarding the accreditation instance of the PDTS, it should be noted that:

- It does not contemplate the set of formal conditions that a characteristic research and development project has (capacity of the director and the team, objectives, methodology, schedule, resources, feasibility, etc.) that are common to the usual research proposals in the SCyTN and that, in short, they are only reflected in the project presentation formats in their respective institutions

- It does not refer to the "internal" criteria for evaluating projects that qualify their intrinsic quality, coherence or internal logic, the appropriate relationship between their components, the adaptation to ethical standards and environmental protection, although it does consider the adaptation to strategic priorities (national or institutional ones) of scientific and technological development

- It meets accreditation criteria that qualify projects based on their contribution in terms of scientifically certified knowledge to solve problems, needs or demands identifiable in society and / or expressed by social agents in the field of politics, the market, territory, culture or social structure

The characteristic of this contribution in terms of knowledge is what will allow a PDTS to be identified and differentiated from other scientific-technological and professional activities that would not be included in the same category of activity.

\section{A. Criteria for accreditation of PDTS}

Specifically, the fundamental criteria to consider for the accreditation of a PDTS are:

\section{Criterion 1: Novelty or Originality}

A research and development project necessarily imply the contribution of new knowledge about phenomena and technological solutions. In this way, originality or cognitive novelty is a central feature of the activity of science and technology. However, this statement must be qualified in the light of the local conditions in which local technological development takes place. The following interpretations of the concept of "novelty" should be considered:

- reconstruction of already existing international technology but inaccessible for local use due to information reserves

- copy or reconstruction of technology with the objective of reducing costs or market price or making it accessible to national productive sectors

- "reverse engineering" as a technology development modality

- punctual application of internationally developed technologies

- adaptation of existing technologies to local usage parameters other than international ones

- application of existing technologies to new objects or functions 
- interdisciplinary projects, in those cases where the complexity of the interrelation between the disciplines involved constitutes a genuine advance of knowledge. Even if the separately contributions of each discipline are not original, it is expressed in the development of patterns of interaction, exchange, cross-fertility of knowledge and, even, in the identification, throughout the execution of the project, of new scientific objects

- taking advantage of strategic opportunities for the technological positioning of the country

- installation or development of scientific-technological services facilities for research

These considerations raise the need to redefine the concept of "novelty" of knowledge, contextualizing it with attention to local conditions. It is, then, to understand the question of originality in the sense of "local novelty".

\section{Criterion 2: Relevance}

The criterion of relevance, more than any other, is related to the objectives of public policy, the sense of urgency or need for the problem to be solved through applied knowledge or the expected impact of the results of technological innovation.

Relevance is a strictly political concept (in a broad sense) and, therefore, does not qualify as intrinsic characteristics of research projects but rather to the objectives or purposes to which it tends and to the objects to which they apply. In particular, relevance may refer to

- the adaptation of the project objectives to public policies or to the strategic objectives of both science and technology policy (national, provincial or municipal) and policies of other areas that affect the production of knowledge (health, industrial policies , agricultural, housing, etc.)

- points of view which are different from those of public policy and linked to policy objectives of civil society sectors or to more or less generalized values in society. It should be noted that this difference can generate contradictions between different orientations that are developed in it, which can be manifested in the objectives of the projects. Examples of this situation are the contradiction between productive and environmental values in relation to agricultural or mining activities

The resolution of the relevance criterion is necessarily in the hands of the institutions that present the PDTS to the BNPDTS according to the priorities that they express regarding their relationship with society, and the same institution may also present projects with different foundations regarding the judgment of relevance.

Criterion 3: Pertinence

If relevance indicates the importance of the objectives of the PDTS in relation to the needs and urgencies of society, pertinence considers whether the research strategy and methodology proposed by the project, as well as the expected results are adequate to solve the problem identified in the location or for the specific use postulated by the project. This is a criterion that links, then, the "internal" conditions of the project with the "external" conditions of the application of its results.

The analysis pertinence of is close to that of the project's ability to achieve the expected results; an analysis that considers the methodology, available resources, accessibility to the object of study, adequacy of human resources, etc. that is typical of any project (basic or applied). However, if this analysis refers only to internal components of the project, the pertinence test contrasts these components with the objective and context of the application of their results.

\section{Criterion 4: Demand}

A key condition of the PDTS is the existence of a demanding agent, an adopting agent, and a project financing agent. In all the areas of knowledge consulted, the existence of demand constitutes proof that the results of the project are of interest to society and not only to the research community from a purely disciplinary point of view.

The concept of demand implies, for this PDTS accreditation operation, the following characteristics:

- the results that the project aims to meet involve a need, a problem or a clearly identifiable purpose in the social, economic, productive, political, cultural, environment, etc., possible to be described qualitatively or quantitatively

- there are agents of the State, society or the market that express interest or concern in the need, problem or purpose object of the project, and this manifestation is explicit

- $\quad$ such agents express an interest in the possible results of the project, even if this does not imply commitment in its adoption

- demand agents are clearly identifiable as individual or collective subjects, and have an adequate level of institutionalization

- since the PDTS accreditation instance is in the orbit of the State, the level of institutionalization of the agents must comply with the current public order requirements and regulations

- the concept of demand suggests the action of requiring a contribution either determined to science and technology organizations and universities to their authorities, bureaucratic structures or through their researchers

- the demand criterion will be satisfied if, in the absence of an explicit request action by the agent, it can be postulated that it has a potential interest in the 
adoption of the results (without implying any commitment of such). In this case, it is a potential adopter

- for the accreditation of the demand and the interest of adoption, the projects that are nominated as PDTS will present sufficient information to corroborate the satisfaction of both criteria

\section{B. The PDTS accreditation mechanism}

Reception of projects for accreditation has the format of "permanent open window" in the SACT. The interested institutions present their projects to be incorporated into the BNPDTS through an ad hoc form, in accordance with the required formality (duly subscribed forms and guarantees), both in paper and digital format. The SACT resolves their admission.

The PDTS candidate projects are studied by the corresponding commission that submits a recommendation to the SACT regarding the status of "Creditable" or "NonCreditable", within a maximum period of 4 months from the date of receipt.

The accreditation committees have an operating regulation [6] and meet on a quarterly basis, to reconcile opinions and issue their informed recommendation. These conciliation meetings are the only instances where commissions can formalize their recommendation. To reach a conclusion, the commission must meet in a conciliation meeting with at least 6 members (quorum). The recommendation of accreditation of a candidate project requires a simple majority of the favorable votes of the members of the commission, with a minimum of 4 (four) favorable votes. Only the projects that reach the majority of the favorable votes among the members present who vote, these votes being more than 4 (four), have an opinion of "Creditable". Candidate projects that do not reach such a majority of favorable votes, have an "Non-Creditable" opinion. Based on these reports, the SACT issues the final accreditation opinion and communicates to the parties.

The institutions that present projects and are not accredited by the SACT, have a formal request for reconsideration, within a certain period, stating the arguments they consider pertinent.

To guarantee the discretion of the projects, the information received, the arguments and opinions and the votes of each and every one of the members, the members of the commission have signed a confidentiality agreement assuming strict professional secrecy.

Conflicts of interest of members of the commission regarding the projects to be analyzed, whether due to their relationship with the project, the institution that proposes it or the executing group, disqualify them from giving their opinion on the projects in question, participating in their treatment in conciliation meetings and sign the recommendation to the SACT. Those members of the commission who maintain a relationship of manifested enmity with the parties interested in the project and those members who expressly request it, also presenting the corresponding arguments, may also be considered in conflict of interest. It is always the commission that determines the condition of conflict of interest for any of its members regarding a project.

\section{CHANGE OF PARADIGM AND THE PENDING CHALLENGE}

Science and Technology in Argentina have been determining factors in the country's growth and international recognition. However, the traditional standards and practices of bibliometric evaluation require scientific and technological researchers to constantly publish articles ("papers") in highimpact international journals, which discourages work in areas of less international relevance, and it makes the production of new knowledge considerably less likely to be inserted in the local productive and social system. Today, however, the country's national reality demands an intimate link and feedback between the scientific technological system and society.

The actions carried out by the MINCyT in order to design a complementary system for the evaluation of science and technology activities, exclusively aimed at personnel dedicated to applied research and social and technological development, which aims to overcome the traditional measurement scheme based on the linear model of knowledge production, and achieving a fair balance between criteria of originality and applicability criteria, constitute a substantial advance in this regard.

These new criteria, which complement the traditional ones, aim to enrich the evaluation system, considering researchers not only in their individual trajectory but also in their insertion and performance in strategic teams and projects for the region, encouraging them to engage in activities of social and technological development, which are treated on an equal footing with basic research at the time of the evaluation. In addition, the consensus reached among the actors of the SCyTN in this regard is, in itself, a relevant political fact, which gives coherence and strength to the system.

The concept above represents, in the first place, an invitation to applied research, to produce solutions to specific problems, thus contributing to the improvement of the quality of life of Argentinians and national development.

Secondly, these actions open the institutional possibility of a new paradigm of evaluation of scientific-technological activities for Argentina. This paradigm would be based on the consolidation of an "Expanded" System of Science and Technology, as it constitutes and expresses the social needs to be satisfied. In addition, in this framework of recognition and assessment of applied research and technological development, Engineering assumes a fundamental role as a source of specific solutions to problems or demands of society, which make the most of the generated knowledge.

The concept of PDTS is a key one in the recognition of the contribution of science and technology to the community, 
establishing a more balanced weighting between basic science and applied science, with the aim of encouraging research to become concrete developments, prototypes or products.

With the implementation of the PDTS, the SCyTN of Argentina incorporates criteria for accreditation of projects based on their contribution to the resolution of identifiable problems, needs or demands in society and / or expressed by social agents in the field of politics, the market, territory, culture or social structure, adopting for this purpose the concept of "local novelty", according to which the originality of knowledge is a characteristic sensitive to local context and conditions.

However, when thinking about the development of a PDTS as an instrument to solve the problems of society, it is worth asking:

¿How can we know or evaluate ex post if the project effectively solved the problem which was posed?

$¿$ What indicators do we have to evaluate the effectiveness of a PDTS?

$¿$ Are these indicators generic and common to all PDTS or special and individual of each discipline?

$¿$ When and how should we apply such effectiveness indicators?

In fact, there are no consensus in the SCyTN regarding the answers to these questions. Nor have conceptual proposals been suggested in Argentina: there are only some generic proposals at international level that evaluate projects from the point of view of the scientific-technological task [7] [8] [9] [10], but they do not address or focus on the degree of contribution to the satisfaction of the demand, the real impact of the project or the effective resolution of the problem in social terms.

Consequently, due to the lack of adequate instruments, the projects presented in the BNPDTS had not been able to be evaluated ex post by the Ministry in terms of their effectiveness in solving the problem in due course. Nor had the scientific-technological personnel affected from them been evaluated by the Ministry. This constituted a weakness for the system because accredited projects presuppose an effective technological development that, however, had not been objectively demonstrated.

In April 2019, the Ministry designed a survey of directors and claimants to have a first ex post approach on the development of projects and the adoption of their results. For this, he used an instrument with closed questions to answer via web. However, this instrument does not use its own indicators of the projects but uses the appraisals of the project actors from both sides. Although this is an important antecedent, as it is the first attempt to know something about the projects once their expected completion date has been met, it does not solve the problem of evaluating the outcome of the projects through appropriate indicators.

It is necessary, then, to have an assessment technology for the PDTS product that includes a set of properly established indicators.
To this end, a Social Technology Development Project capable of contributing to the foundation, design, and validation of a relevant evaluation technology for the scientific-technological evaluation scheme inaugurated with the introduction of the PDTS concept must be defined and executed.

This Project should have, among other objectives:

- It should develop a Specific Theoretical Framework (or "Local Theory") of the PDTS that allows: (i) to understand the meaning and scope of the concepts introduced in the regulations, namely "local novelty", "relevance", "pertinence" and "demand", its interrelations and connections with related concepts such as "social utility" and "knowledge mobilization"; (ii) conceptually place the novelty that represents the initiative of the PDTS in the context of national and regional scientific policies generated from the crisis of the so-called "linear model" dominant since the mid-twentieth century; and, (iii) establish contact with the recent academic production in the field of social studies of science

- It should design, on this basis, an Evaluation System for social and technological development activities within the framework of current regulations. This System should serve ad-intra universities and the SCyTN, to adequately assess the effectiveness of such projects in terms of their social impact and their contribution to the resolution of real society problems. The system will include a set of indicators and procedures (a true "Evaluative Technology") in accordance with: (i) current regulations; (ii) specificities of an evaluation that deviates from bibliometric methods and the use of "peer evaluation", as usually occurs in basic research; and, (iii) the possibility of implementing alternatives such as the "extended peer community", which have emerged within the framework of perspectives such as the "post-normal science" developed by Funtowicz and Ravetz [11]

- Validate the Evaluation Technology through consultations, surveys, in-depth interviews, and other related methods with key SCyTN actors, members of the Accreditation Commissions, PDTS directors, claimants, and adopters.

To sum up, the challenge is to specify a Social Technological Development Project that has as its product, an Evaluation Technology capable of being applied for the ex post evaluation of the PDTS. This implies a series of changes in the current conceptual paradigm of ex post evaluation of projects.

In fact, the incorporation of the PDTS and the accreditation process involved represent an innovation with respect to the traditional practice guided by the so-called "linear model" of scientific-technological policy. In this model, the Relevance of an investigation is directly associated 
with the production of knowledge that contributes to the progress of the discipline. Consequently, the scientific evaluation has been carried out only by experts, usually based on bibliometric criteria, which privilege publications in highimpact international journals.

The accreditation of the PDTS incorporates a concept of Relevance associated with the urgency or need of the problem to be solved through applied knowledge and / or the expected impact of the results of technological innovation. Relevance, in the new framework, is a strictly political concept, and, therefore, its evaluation involves the objectives or ends to which it tends and the objects to which they apply. This political conception of Relevance is conceptually articulated with innovations in two other key aspects of any project, namely, the "originality of the knowledge that it is proposed to produce" and the effectiveness (that is, the combination of efficacy and efficiency) of the same one. In the framework of the PDTS, both characteristics are no longer treated as purely "internal" characteristics of the projects: their evaluation involves an appropriate consideration of the "context".

In the evaluation of "originality" the reference context is not the frontier of disciplinary knowledge according to the consensus of the corresponding scientific communities but the context of application and implementation of social and technological development. In this case, the "originality of the new generated knowledge" is a characteristic strictly dependent on the local context. For this reason, the element of "originality of the knowledge to be produced" (usual as a requirement in basic and postgraduate research projects) is replaced by that of Local Novelty, which clearly expresses its link with the Relevance.

The evaluation of the "effectiveness of a project" is replaced by a Pertinence one; this refers to the way in which the methodology, the available resources, the accessibility to the object of study, the human resources involved and other characteristics of a research project are consistent and adequate, not only with its objective but with the "context of application" of the results. The Pertinence of the project expresses the result of a contrast between the internal characteristics of the project (usually addressed by the Research Methodology) with the "external" conditions. In other words, it represents an evaluation of "effectiveness and efficiency in the local context of application of the results". The "triangular articulation" between the central criterion of Relevance with those of Local Novelty and Pertinence has two key consequences: the first appears as an accreditation requirement, the second as a requirement of conceptual coherence.

First, the ex ante accreditation of the Relevance requires the existence of applicants and effective or potential adopters. This presupposes the active incorporation into the process of creating the Local Novelty of new social actors not included in the basic research management processes within the framework of the "linear model".

Secondly, the ex post approach to the results of the PDTS faces the challenge of developing mechanisms for the participation of those actors that allow the evaluation of the articulated achievement of Local Novelty and Relevance.

\section{CONCLUSIONS}

The incorporation of Social Technology Development Projects into the Argentinian National Scientific and Technological System means a substantial advance in its evaluation criteria and mechanisms. Complementing the traditional evaluation paradigm based on the "linear model" with the weighting of the production of knowledge that is carried out through the development of technology, in particular, when it has a true impact on society, it constitutes an improvement of the System as such and a policy of recognition and promotion of technological development in the country.

Current regulations and the implementation of the System have been successful, reliable, and robust. In addition to consolidating the concept of Social Technological Development Projects, it has managed to generate an interinstitutional consensus on this and sustain a State of Science and Technology policy that has survived different governments.

Under this new paradigm of recognition and evaluation of applied research and technological development, Engineering assumes a fundamental role, providing concrete solutions to specific problems, exploiting the generated knowledge to the maximum.

With the consolidated system, there is now the challenge of advancing in the mechanisms of ex post evaluation that presuppose changes in the prevailing paradigm of evaluation of Science and Technology.

The ad hoc instrument is nothing more than, precisely, a Project of social technological development capable of contributing to the foundation, design and validation of a relevant Evaluation Technology for the scientifictechnological evaluation scheme inaugurated with the introduction of the concept of Social and Technological Development Projects. This starts the second generation, depending on the degree of maturity of the System, the recognition and evaluation of the genuine contribution of technology to society in Argentina.

\section{ACKNOWLEDGEMENTS}

This article is based on a PhD Thesis Project in Science and Technology of the National University of Cuyo that develops the first author under the direction of the second author. The authors express their gratitude to the Faculty of Engineering of the National University of Mar del Plata and the Faculty of Engineering of the FASTA University for their invaluable support for the Project.

The authors also appreciate the collaboration of Professor Silvia Nigro in the translation of the work. 


\section{REFERENCES}

[1] Documento I de la Comisión Asesora sobre Evaluación del Personal Científico y Tecnológico: Hacia una redefinición de los criterios de evaluación del personal científico y tecnológico. Ministerio de Ciencia, Tecnología e Innovación Productiva. Agosto 2012. República Argentina. https://www.argentina.gob.ar/sites/default/files/documento-i-de-lacomision-asesora-del-mctip.pdf. Accessed February 72020.

[2] Documento II de la Comisión Asesora sobre Evaluación del Personal Científico y Tecnológico: Precisiones acerca de la definición y los mecanismos de incorporación de los Proyectos de Desarrollo Tecnológico y Social (PDTS) al Banco Nacional de Proyectos del MCTIP. Ministerio de Ciencia, Tecnología e Innovación Productiva. Agosto 2012. República Argentina.

https://www.argentina.gob.ar/sites/default/files/documento-ii-de-lacomision-asesora-del-mctip.pdf. Accessed February 72020.

[3] Banco Nacional de PDTS. Ministerio de Ciencia, Tecnología e Innovación. https://bancopdts.mincyt.gob.ar/proyectos/bancoPdts.zul Accedido Accessed February 72020.

[4] Banco Nacional de PDTS en cifras. Ministerio de Ciencia, Tecnología e Innovación. https://www.argentina.gob.ar/ciencia/bancopdts/pdts-encifras Accessed February 72020.

[5] Nómina de Proyectos acreditados en el Banco Nacional de PDTS. Ministerio de Ciencia, Tecnología e Innovación. https://bancopdts.mincyt.gob.ar/proyectos/bancoPdts.zul Accessed February 72020.

[6] Reglamento de las Comisiones de Acreditación de los Proyectos de Desarrollo Tecnológico Social. Resol 2017-118-APN-MCT. Febrero 2017. República Argentina.

[7] Manual Iberoamericano de Indicadores de Vinculación de la Universidad con el Entorno Socioeconómico - Manual de Valencia (RICYT 2017).

[8] Normalización de Indicadores de Innovación Tecnológica en América Latina y el Caribe - Manual de Bogotá (RICYT 2001).

[9] Pautas para la interpretación de los datos estadísticos disponibles y la construcción de indicadores referidos a la transición de Iberoamérica hacia la Sociedad de la Información - Manual de Lisboa (RICYT 2009)

[10]Manual de indicadores de internacionalización de la ciencia y la tecnología - Manual de Santiago (RICYT 2007).

[11] FUNTOWICZ, Silvio O; RAVETZ, Jerome R. "La ciencia posnormal. Ciencia con la gente". 2000. Icaria, Barcelona.

Digital Object Identifier: (only for full papers, inserted by LACCEI). ISSN, ISBN: (to be inserted by LACCEI). 